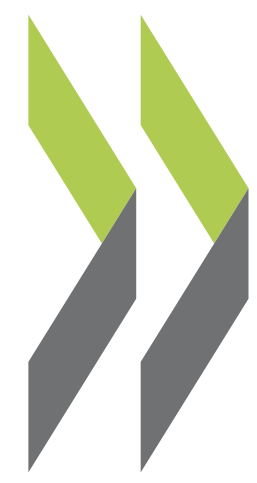

PEB Exchange, Programme on Educational Building 2000/10

\title{
School Premises \\ and Violence
}

\author{
Michel Born
}

https://dx.doi.org/10.1787/833054225153 


\section{SCHOOL PREMISES AND VIOLENCE}

The following article was contributed by Professor Michel Born from the Department of Psychology of Delinquency and Psycho-social Development at the University of Liège, Belgium. PEB would be interested to receive reactions to his views and asks readers to send feedback to the Secretariat.

The eruption of violence in society is a natural phenomenon; its rise or fall depends on complex, interrelated social processes. The same applies to violence on school premises, any study of which must address the individual characteristics of young people who perpetrate violence and the specific social context of the school. Violence is a generic term, covering violence towards property as well as people. When we speak of violence towards property, we mean acts of defacement, vandalism, graffiti, etc. In the case of violence against people, we make a distinction between verbal violence and physical acts of violence (fights, assaults, etc.), whether directed towards other pupils or teachers.

\section{Violence amongst young people}

Like any form of delinquency, violence can be experimental, particularly during adolescence - and therefore in schools - but it may also continue throughout different periods of life.

\section{Discontinuity}

Non-habitual violence is exceptional and results from a particular situation. It is part of a process culminating in a crisis, in the sense in which this is understood by the Belgian criminologist De Greeff. It normally occurs where the individual experiences conflict or tension, though it can also be a group phenomenon. Although it may sometimes have serious consequences, it is an isolated act, occurring where the individual's relationships develop in such a way that violence erupts in a given situation. It arises, for example, where temptation is too great or where there is a crisis induced by alcohol. It may take the form of shouting, slamming doors, kicking walls, slapping, punching and more serious assaults.

\section{Developmental violence}

Such violence reflects the absence of any link between the person and society. Its origin is to be found in childhood, for example where parents are themselves violent, or where there is a general lack of respect for the law in the immediate domestic or social context.
In adolescence, violence is often aggravated by the peer group, which provides role models and encourages anti-social behaviour, seen as conferring prestige. Violence then becomes an habitual way of reducing personal tension or a way of life through which the individual asserts himself or herself.

\section{Scale of the phenomenon}

Statistical studies (based on surveys and data provided by the authorities or the police) clearly show that violence in schools is a reality. This is nothing new; we might recall that in François Villon's time, pupils were told to leave their daggers in the cloakroom before entering classes.

United States statistics for 1996, published jointly by the Departments of Justice and Education, show that 12- to 18-year-olds committed 225000 serious crimes not involving homicide (rape, assault, armed assault) on school premises, and 671000 outside school. Furthermore, $12 \%$ of the students in the last year of secondary education said they had been attacked by unarmed assailants, while $5 \%$ said they had been victims of armed attacks, either on the school premises or on the way to or from school. As for headteachers, $10 \%$ reported serious incidents to the police and $47 \%$ complained of "minor" offences (vandalism, theft, etc.). It should be pointed out that primary schools experience less vandalism, which occurs mainly in urban secondary schools. In the period 1992 to 1994 , i.e. in two school years, 76 murders or suicides were recorded in school or on the way to or from school, which is small compared with the total number of murders of young persons (aged between 5 and 19) in the same period (7 357). During the school year 1993/94, 341000 teachers $(12 \%)$ complained of having been "abused", and 120000 (4\%) said they had been victims of physical assault.

In France and Belgium, the situation is fortunately less serious. Nevertheless, several studies (see Bernard Charlot and Jean-Claud Emin, Violences à l'école : États des savoirs, Paris, 1997) have clearly shown that the phenomenon is widespread, even if some schools are more exposed to it and others protected from it.

\section{Attempt at an explanation}

The changes in western society have undeniably encouraged a considerable, almost unlimited, growth in opportunities for delinquency, whether through the availability of goods of all kinds and the ease of access to them, or through the massive increase in appropriate resources (transport, weapons, computers). Being democratic and liberal, 


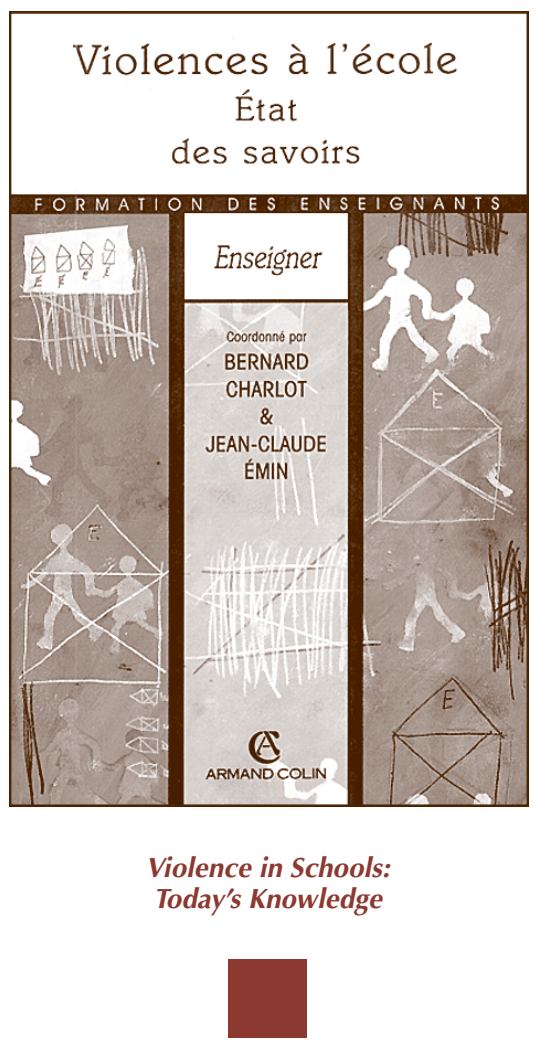

society offers opportunities to whoever wishes to take advantage of them. The role models presented by the media are often violent, and barriers to delinquency no longer take the form of obstacles imposed from outside (parents, school, police) but of obstacles freely consented to and internalised. The individual must draw upon his or her system of moral references to find effective obstacles to behaviour that falls outside socially accepted standards. School has become the one place where the references underlying individual action are acquired, like a moral beacon serving as a guide to individual action. These points are relevant not only to schoolchildren but to citizens in general, and thus to society as a whole. This system of references is not dissociated from any context but is of general relevance. The references acquired at school are related to all aspects of life in society; if they were not, social values would not extend beyond the school precincts. Schools would not be fulfilling their role and would be legitimate objects of protest or even attack.

Children and adolescents are thrust into a society whose system of values varies according to period, culture and current events. This is a cultural legacy, built up over generations, with the shifts in society's values producing a strong impression of inconsistency, particularly during certain periods, such as the present day. In today's school system, values are rarely presented affirmatively. The reason for this is the reaction against what had formerly been a bar to freedom. Traditional values and institutions - state, church, school, marriage, justice, police - have also been called into question; confidence in democracy is in decline.

Some adults, feeling that authoritarian, dogmatic attitudes are outdated, abandon their children to moral relativism. Children need guidance, however, and it is therefore essential that they be provided with clear, strongly held values.

Learning to control oneself is a fundamental requirement in western democratic societies. There has been a shift away from control imposed from outside (the law, the police) towards control exercised autonomously and freely accepted (responsibility). Unfortunately, not all citizens have adequately mastered the process of referring to a value system. Such mastery presupposes an advanced level of moral development, based on social awareness and substantial powers of self-control, which are by no means universal in adolescence or even in adulthood.

\section{The school premises}

The school is required to develop the individual's powers of autonomous control in his or her interaction with society and life within a group. Whatever the age of the child, the school buildings and the outdoor areas of the school may or may not provide the opportunity for the exercise of control.

The school should be a place where children are prepared for society. But it should not be closed in upon itself like a fortress, so that such preparation is conducted in an isolated environment that bears no relation to the realities of our society. On the contrary, the preparation should involve a process of social awakening, in which the children are made aware of the world and the world is present to them. The school should therefore enter into a symbiotic relationship with the surrounding district. Leaving aside the ideological conflict over the comparative merits of "closed" structures that are cloistered and isolated, and structures that are "open" to other areas, and thus to society, we know that:

- The trend in contemporary history is towards openness.

- Opening up the school does not necessarily imply pedagogical innovation.

- Open areas are more appropriate to those with an advanced degree of autonomous control.

- Autonomous control is not directly related to age in the development process. 
- Open structures, by definition, provide those who are not at ease in the establishment with the possibility of escape; however, they also allow access to persons whose intentions are reprehensible.

\section{The school premises are the scene of preventative action}

A telling example of intervention in a school is provided by Michel Floro in Questions de violence à l'école, Eres, 1996. First of all, thorough research was carried out in order to identify the problems; after that, strategies were worked out and applied; lastly the situation was evaluated. The opinion of the educational establishment was sought regarding the layout of the premises. An administrator was appointed and two target areas were designated: the playground and the canteen. Several changes were made:

In the playground:

- Game rooms were set up, used by different classes in turn during break-time. This area was decorated by the children with a fresco; cupboards were installed in the corridor.

- The entrance hall was renovated: it was cleaned and painted, and children's work was exhibited; the means of access to classrooms were increased.

- A garden was laid out.

- A running track was laid down, and basketball facilities were installed.

In the canteen:

- Better management of time was instigated: two sittings were introduced.

- The canteen was transformed with the fitting of moveable partitions.

- Old furniture was replaced with furniture that could be moved more quietly.

The results were very positive: jostling and fighting disappeared from the playground and the corridors (violence persisted only in the street after school), and food was no longer thrown around in the canteen. Achieving this result had required consistent action and simultaneous work on two fronts: refurbishing the areas and encouraging participation.

\section{In conclusion}

Consequently, even if the trend in the ideology and history of democracy is towards open areas, we should not act naïvely. It is necessary to create protected areas, as well as places that are not visible (not "tempting"), properly isolated storage spaces allowing controlled access, parts of buildings that can be isolated from the rest, materials that do not lend themselves to defacement or graffiti and can be restored easily and cheaply, as well as the will to keep them in good condition (the well-known broken window syndrome). Above all, everybody in the school community (teachers, pupils, parents) in association with the local residents, must ensure that moral development and social responsibility are incorporated into the process of acquiring skills and knowledge.

The school, in view of its underlying principles, should be regarded as the property and the "flagship" institution of the community as a whole (those associated with the school and local residents), forming part of a dynamic system; every system seeks to achieve a balance between its constituent elements and between itself and the outside world. Interpersonal relations require material conditions, which are not the same in an open system as in a closed one. Everybody needs and seeks security, but children adapt to change more quickly than adults. All depends on securing balance, i.e. the appropriate relationship between the different elements, and harmony, i.e. the proper management of this relationship.

Given the changing conditions, we need an "ecology" for schools, providing a secure space in which persons and groups can engage in collective activities, discover their identity, acquire citizenship and forge social bonds, the only effective cure for violence.

Article contributed by:

Professor Michel Born

University of Liège

Psychology of Delinquency and Psycho-social Development

Boulevard du Rectorat B-33

$B$-4000 Liège, Belgium

Fax: 3243662988 